\title{
The archaeology of political corruption in Nigeria
}

\begin{abstract}
The research of Arno Boenner focuses on political corruption as a major issue. The analysis of this topic, however, often neglects to explore the role played by imperialism. $\mathrm{Dr}$ Boenner considers whether there is a causal connection political corruption before offering an ethics based form of governance as a potential solution. By applying a selfdeveloped criteria catalogue he identifies spaces, which in all stages of history show a lack of accountability and transparency. In political and economic of interact without being held accountable. From a global perspective, the analyses provided by the author can be considered as a strong contribution to the formation of a theory of corruption.
\end{abstract}

\section{0}

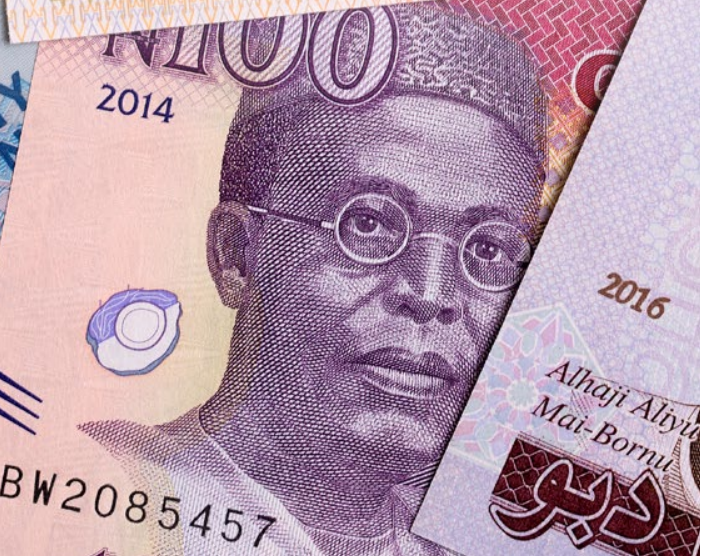

Ithough well researched, a gap CORRUPTION AND remains in our understanding
of political corruption. This is political corruption in particular lacks theoretical foundation. Dr Arno Boenn takes a closer examination of the history of corrupt countries, focusing on the colonial past of politically corrupt nations. Rather than examining nations context should be examined focusing on imperialism, including analysis of the colonising country and the colonised country. The work can be regarded as a special case of international relations, as it deals with the interplay between foreign companies, the Nigerian state, and its colonial predecessors The essential theoretical foundation is laid by historical institutionalism, which deals with the historical genesis of institutions. His study takes an interdisciplinary approach as historica institutionalism is combined with economic, sociological, philosophical, historical and Marxist-inspired theories and explanatory approaches.

Dr Boenner's work is published in Nigeria - An Archaeology of Political Corruption. Despite being independen for many decades, the current state of history as part of the British Empire. Dr Boenner argues that Nigeria's present political corruption is rooted in the permissive legislation for jointstock companies during the mid-19th century Manchester Liberalism. These corporations, settling in the Niger
Delta in the 1880s, represent the Delta in the 1880s, represent the forerunners of the Nigerian state, laying the foundation of political corruption. Political corruption is the product of a continuous interplay between the state of Nigeria, its colonial precursors and foreign companies operating on
Of the 50 most politically corrupt countries, 25 are within the African continent. Except for a few countries, many were formerly part of European empires, leading Dr Boenner to question whether there may be a causal link. Could the corruption that exists in by the British?

Much political research focuses on Nigeria as it exists from independence historical context that contributes to the functioning of present-day institutions. Dr Boenner examines more than 120 years of Nigerian history to discover whether the seeds of corruption were sown during the colonial years. He identifies a gap in research regarding the perception of political corruption as a cross-cultural and cross-continental historical phenomenon that isn't deat with systematically. Therefore, the analysis does not begin in the present nor in Africa, but in Europe before imperialist expansion. In essence, Dr between imperialism and corruption.

\section{ORIGINS IN VICTORIAN BRITAIN} To test this hypothesis, Dr Boenner Africa. In the 1830s, Britain embodies an economic approach of Manchester Liberalism. This is a laissez-faire mindset, arguing for low regulation and free trade. During the Victorian age, this was regarded by many as the route towards a more equitable society. Britain, more than its European neighbours, favoured this mode.

However, research into this period eveals a high level of political corruption, exemplified by 1840 s railway
mania. Dr Boenner's research argues that

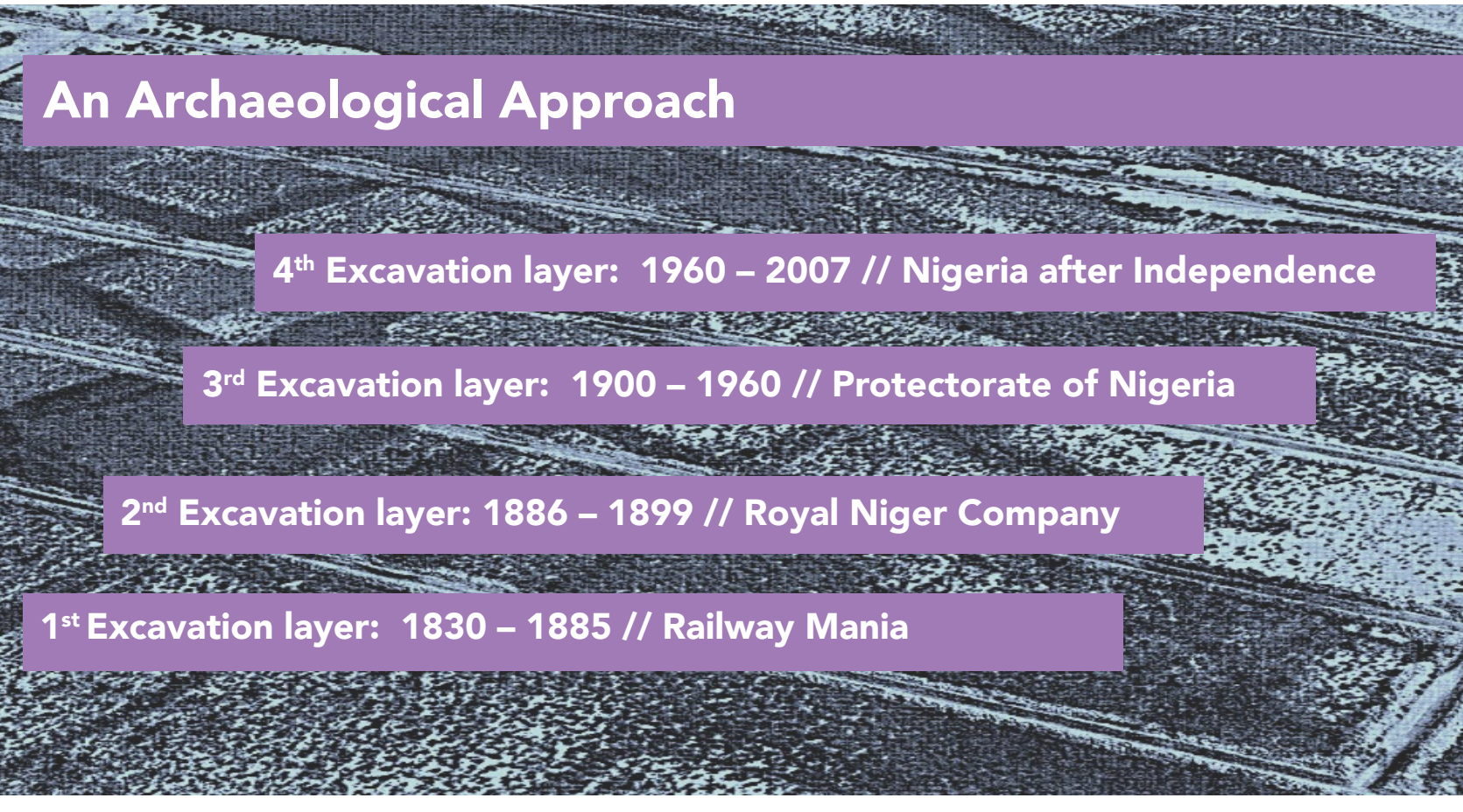

Dr Boenner's methodology is an archaeological approach to the history of Nigeria's system of government. He divides history into four distinct
periods, examining each one in isolation.

his corruption was exported to Africa during the colonial years, supported by a permissive joint-stock company law. At the end of the 19th century, foreign joint-stock companies began to base themselves in Nigerian territory, pursuing commercial objectives, first, by establishing trade relationships and, second, by claiming territory Company rule was first executed by British corporations rather than forma colonial rule.

AN ARCHAEOLOGICAL APPROACH Dr Boenner's methodology is an of Nigeria's system of govo the history divides history into four distinct periods examining each one in isolation. Using six criteria catalogue, each time period is examined to uncover the extent to which corruption exists. This helps to pinpoint the origin and perpetuation of corruption in the country and find solutions to it.

First Period: Spans from 1830 to 1885 , before Britain expands into Nigeria. It is a time of sustainable economic and technological progress. The Industria Revolution is in full swing, leading to a phenomenon referred to as railway mania. Due to the vast amount of wealth involved, legislation is often incomplete, alowing businesses to do what they

liberalism, Dr Boenner suggests, contributes to the emergence of a system prone to corruption.

the Royal Niger Company Army.

Third Period: This begins in 1900 and 1886 to 1899 is when the Royal Niger lasts until Nigeria gains independence Company expands into Nigeria and in 1960. The territory conquered by the develops business activities. Dr Boenner Royal Niger Company is designated is particulanly interested in how the Royal as a regular protectorate, allowing Niger Company, a business with roots British companies to do business freely in Britain, takes over the Niger Delta. with little regulation. This creates the The Royal Niger Company is a jointstock company endowed with a royal a governmental organisation pursuing

groundwork in which systemic corruption can flourish.

Fourth Period: The period under

\section{Nigeria's significant governance deficits} were initiated in the former colonial motherland of Great Britain.

Klitgaard's Corruption Equation

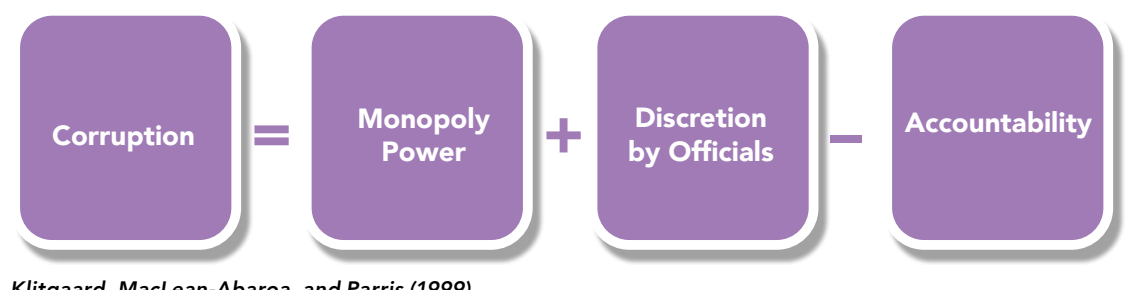

Kiltgaard's equation shows that potential negative effects of monopolies and discretion can be 


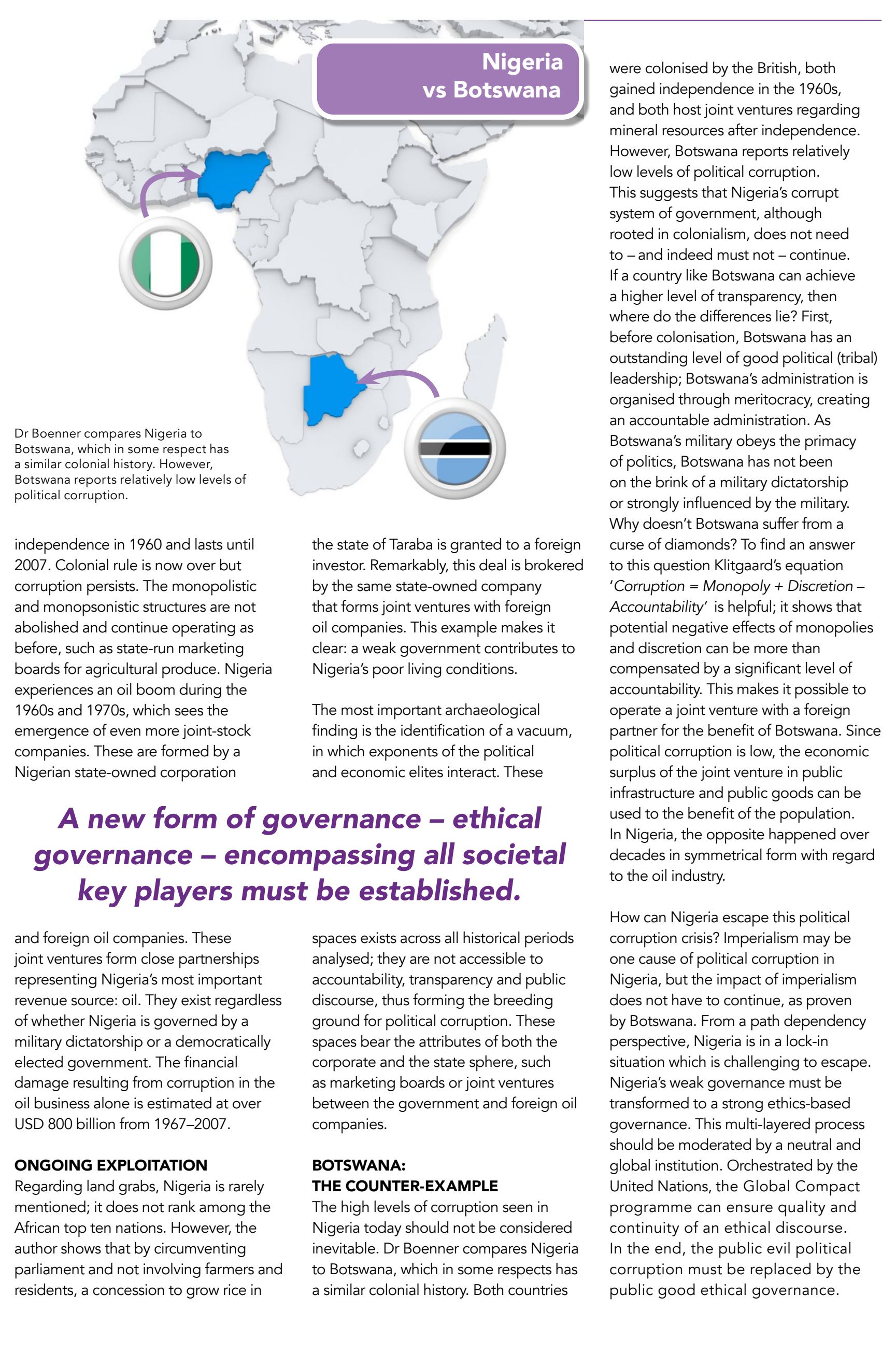

\section{8 \\ Research Objectives \\ Dr Arno Boenner researches the historical roots and connection between imperialism and political corruption \\ References}

Bönner, A. (2020). Nigeria - An Archaeology of Political Corruption. Berliner Wissenschafts-Verlag. pp 1-323.

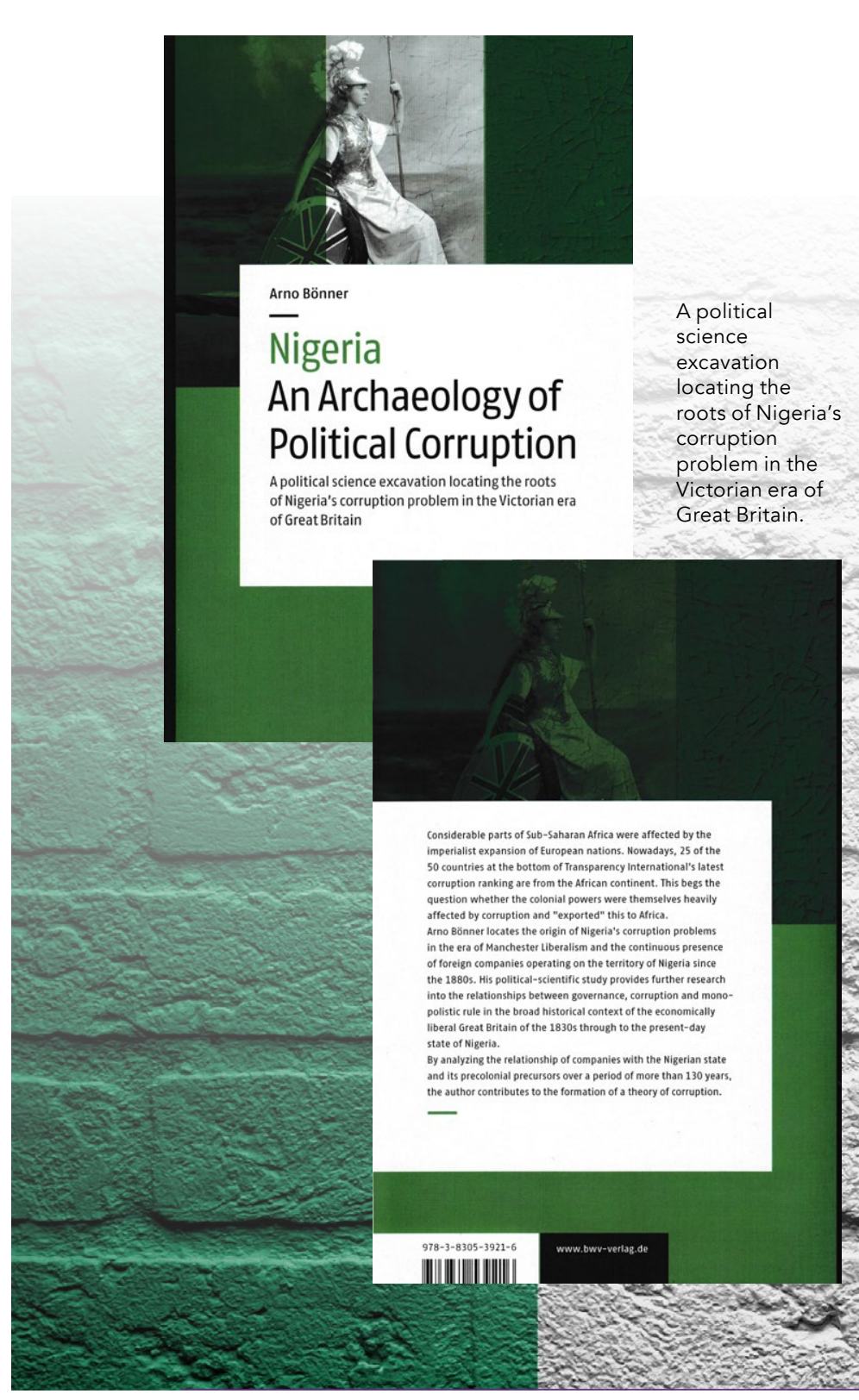

\section{Detail}

Dr Arno Boenner, born 1968, studied business administration at the Universities of Marburg and Giessen, Germany. 2015 Doctorate in Social Sciences, Institute of Political Science, University of Wroclaw, Poland. Business professional with globa players, specialising in IT applications and analytics since 1998.

Funding

\section{Personal Response}

How have some postcolonial countries, such as Botswana, managed to avoid the levels of corruption seen in Nigeria?

II In the case of Botswana, the following key success factors could be identified: After independence a sustainable transition of (colonial) technocratic and Botswana's judiciary has proved to be independent from influences of the executive, thus contributing strongly to high scores of rule of law. Botswana's administration is organised strictly applying meritocratic principles, thus laying the fundament for high levels to constitutional tosks and responsibilities, obeying the primacy of politics and not claiming government power. Among others, these success factors enable the try to reach low levels of corruption and to operate international joint
of Botswana.

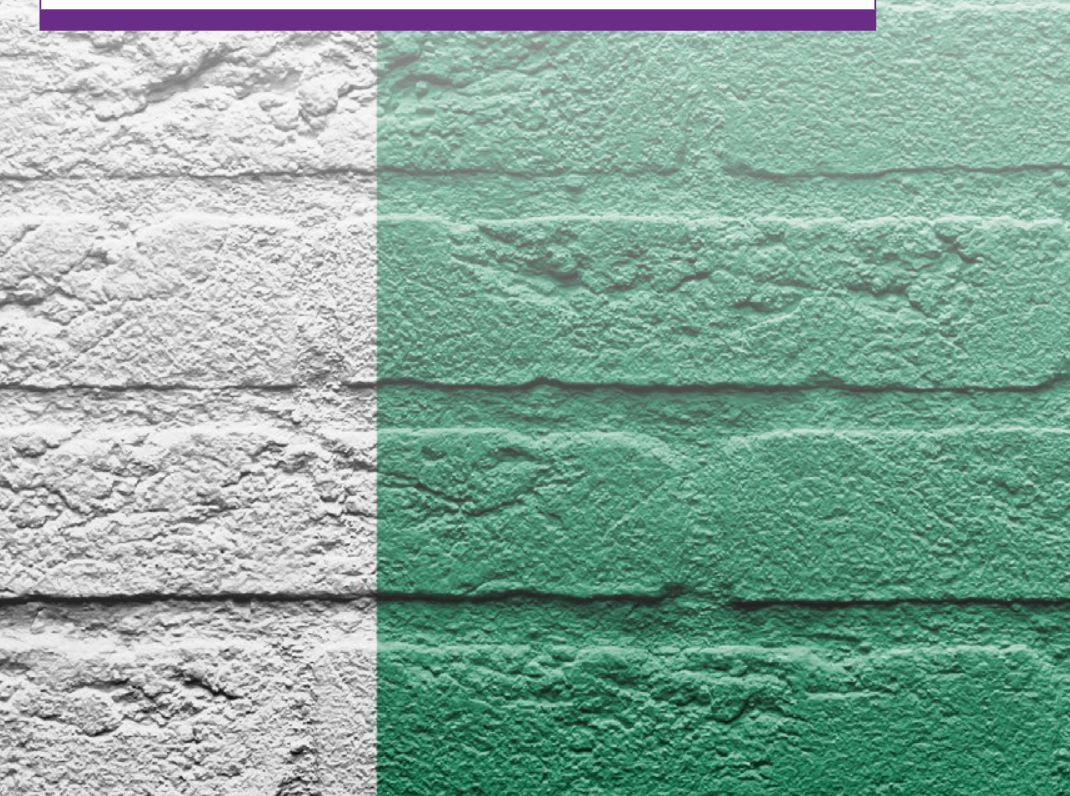

